This item was submitted to Loughborough's Research Repository by the author.

Items in Figshare are protected by copyright, with all rights reserved, unless otherwise indicated.

\title{
The impact of higher wage floors on labour markets
}

\section{PLEASE CITE THE PUBLISHED VERSION}

http://www.agendapub.com/books/political-economy?view=title\&id=18

\section{PUBLISHER}

Agenda Publishing

\section{VERSION}

AM (Accepted Manuscript)

\section{PUBLISHER STATEMENT}

This work is made available according to the conditions of the Creative Commons Attribution-NonCommercialNoDerivatives 4.0 International (CC BY-NC-ND 4.0) licence. Full details of this licence are available at: https://creativecommons.org/licenses/by-nc-nd/4.0/

\section{LICENCE}

CC BY-NC-ND 4.0

\section{REPOSITORY RECORD}

Hirsch, Donald, and Laura Valadez. 2019. "The Impact of Higher Wage Floors on Labour Markets". figshare. https://hdl.handle.net/2134/24065. 


\section{Chapter 3 The impact of higher wage floors on labour markets}

The exchange of a person's labour for a wage is a voluntary transaction between a worker and an employer at an agreed price. If the price is artificially set at a higher wage rate than the employer is willing to pay, the employee will not be hired. This simple truth causes some free market economists to argue against any 'wage floor' (a minimum or living wage) that seeks to adjust wages according to any criterion other than the free operation of the labour market. To do so risks destroying jobs.

While that is the conclusion of neoclassical economic theory (on which prevailing modern economic models are based), many economists have suggested that in practice, the world is not that simple. The way that wages are actually fixed only imperfectly reflects what firms could pay for labour and still make a profit. The bargaining power of workers and employers is unequal. In some cases the ability of workers to move to higher-paying jobs if their work is undervalued (as market theory would predict) is restricted, sometimes because their firm is the only one hiring for a particular job type in a local area. Moreover, even if as the theory predicts, a rise in wages causes a fall in employment levels, the size of these effects needs to be taken into consideration. In 2015, the UK government announced a large increase in the minimum wage for over- 25 year olds by 2020 . It estimated that this would eventually result in pay rises for six million workers, but reduce jobs growth by 60,000 (Office for Budget Responsibility, 2015, p204). If that proves true, for every hundred people whose pay increases, one job (which does not yet exist, but theoretically would have by 2020) will not be created. Many people might think this is a reasonable way of improving workers' lives overall, rather than insisting that no pay increase can ever be worthwhile if it means fewer jobs.

This chapter considers the effect of wage floors on the labour market. 'Wage floor' is here taken to mean any minimum pay rate that is agreed or enforced outside the context of market bargaining. Evidence of the effect of wage floors is most clear-cut where a minimum wage is imposed by law, and much of the evidence relates to minimum wages set as statutory requirements within particular countries or regions. A living wage adopted voluntarily by employers on the basis that it is right to pay enough for people to live on can also be regarded as a wage floor that over-rides market bargaining. However, its impact can be harder to measure, partly because the decision by employers about whether to adopt a voluntary living wage is bound to be influenced by whether they think it is affordable. Nevertheless, those putting pressure on employers or governments to put any kind of 'artificial' floor on wages need to consider the overall potential impact on the labour market of not allowing the market wage to prevail. This explains why much of this chapter looks at evidence on minimum wages rather than living wages, yet why such evidence is crucial for the subject of this book. Indeed, it could be argued that current efforts in the United States (from where much of this evidence derives) to restore minimum wages to more adequate levels after years of decline in their value represents a revival of Franklin Roosevelt's mission to make a minimum wage a living wage.

The chapter starts by summarising theoretical arguments and counterarguments about the potential adverse effect of wage floors on labour markets. It then considers what recent evidence has shown about, firstly, the effect on employment, and next on wider effects on employer and employee behaviour. The chapter concludes by reflecting on which consequences of setting wage floors are considered acceptable and unacceptable, by whom and why.

Free markets and market imperfections: economic arguments against and for minimum wages 


\section{The textbook model of supply and demand}

Neoclassical economics suggests that as long as markets are allowed to operate freely, resources will be deployed most efficiently through the interaction of supply and demand to determine market prices. In the case of labour, figure 3.1 presents the basic textbook model, and shows what happens if an enforced wage floor overrides the negotiated market price.

Figure 3.1 - Basic laws of supply and demand determine that compared to a free labour market, minimum wages cost jobs

(This simple case represents supply and demand for unskilled labour in a given industry)

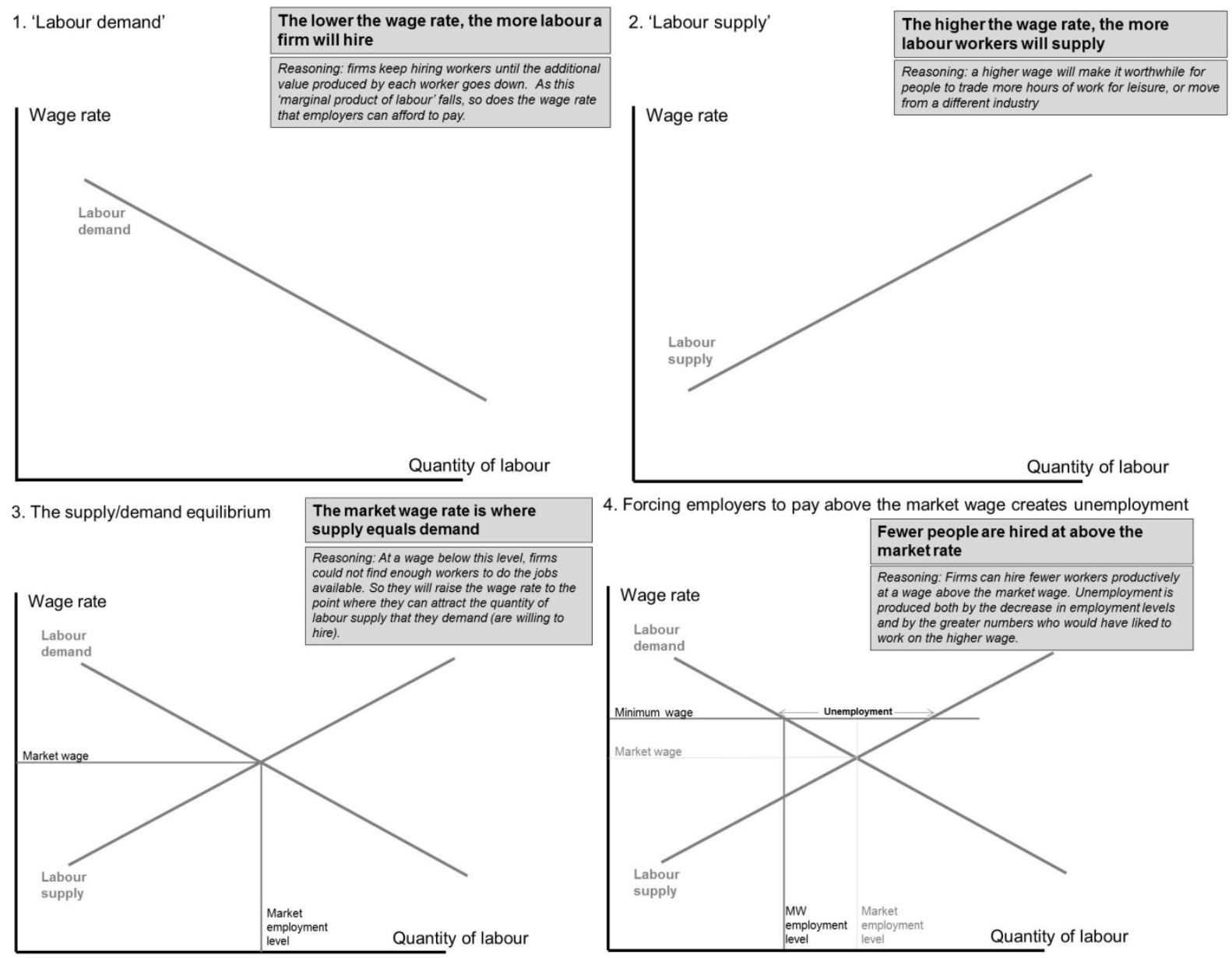


In the basic economic model, buyers will usually 'demand' (be willing to purchase) more of something the lower the price they can get it at; conversely, sellers will supply more of it the higher the price they can sell it for. These opposite relationships will produce an 'equilibrium price' at which the demand and supply lines intersect: buyers are willing to purchase the same amount as suppliers wish to sell. This is also described as the 'market clearing' price, since everybody wishing to buy or sell at this price can do so.

In the case of labour markets, if wages are initially lower than the market rate shown in the third panel of Figure 3.1, some buyers/employers will be short of labour and be willing to bid the price up in order to secure workers from their competitors. If wages are too high, fewer jobs will be made available than workers want, so some will be willing to accept work at a lower wage, rather than be unemployed, and so bid down wages. Adjustments of this type occur until the equilibrium is reached.

A minimum wage set above the equilibrium, as in the final panel of Figure 3.1, will reduce employment and prevent some people willing to work at this rate from finding a job, causing unemployment. This will be the result of firms investing less in creating the jobs shown here, and redeploying capital for other purposes. While sometimes this can mean investing in more productive jobs (see below), making labour more expensive can also incentivize a switch in investment towards more 'capital intensive' forms of production, meaning that it becomes relatively more economical for firms to invest in machinery and equipment rather than in workers to enhance output.

A central concept in the model explaining market wages is the marginal product of labour. This refers to the additional output that a firm can gain from hiring an additional worker. This helps determine labour demand and therefore the wage a firm is willing to pay. It is assumed that production is increased to a point where the marginal product of labour diminishes (because production capacity is stretched, so each additional worker adds less), producing the downward slope in labour demand shown in Figure 3.1.

\section{Limitations in the textbook model}

Economists recognise that the above model is a great oversimplification of how labour markets actually work. Importantly, it looks at a single industry in isolation and imagines labour to be homogeneous (such as where unskilled hands are needed to work machines in a factory). This means for example that it takes no account of the quality of labour, or the scope for raising productivity to fund higher wages, whether by investing in better equipment or in worker skills. Economic literature recognises a great number of complexities in labour markets in practice, and it requires a study of labour economics to start to appreciate the many interactions involved. Here, it is sufficient to note six key factors that could influence the relationship between wages and employment, other than those shown in the model illustrated in Figure 3.1.

1. Even taking the model as accurate, the sensitivity of employment rates to wages can vary greatly. This depends in particular on the slope of the labour demand line shown in the diagram: if it is steep, the difference between the minimum wage employment level and the market employment level shown in the final panel will be small. A steeply sloping labour demand line means that relatively few additional jobs can be created by lowering wages by a 
given amount, suggesting that the marginal product of labour falls rapidly above a certain level of employment. This could occur for example if an additional worker is hired in a factory where machines are already being used to the maximum, or if an additional nurse is taken on in a hospital unit where a shortage of expensive medical equipment is causing a bottleneck in throughputs. Economists refer to this as low price elasticity of demand in labour markets, meaning that the quantity of labour that firms are willing to hire is relatively insensitive ('inelastic') to wage rates. The level of this elasticity has therefore been a focus of studies on the effects of minimum wages.

2. In practice, labour markets have many 'imperfections', that do not fit the model. In particular, there is imperfect competition between employers. Under 'perfect' market competition, an employer cannot pay a worker less than the marginal product of their labour (how much they add to output), because another employer would offer them a higher wage. In reality, competition is constrained by the fact that workers cannot always readily switch employers.

One important reason for this is that there may not be another employer buying the same kind of labour close to where people live. This is referred to by economists as monopsony: just as a monopoly is where a market is dominated by a single seller, a monopsony refers to a single buyer - in this case of labour. An industrial revolution worker employed by the town's only cotton mill had little or no choice of working elsewhere, so their employer could set a wage below the rate that would have existed under market competition. In this case an enforced higher wage might not require the employer to cut back on jobs to ensure that workers produced the value of their wage, since previously they were producing more on average than it cost the employer to hire them and still make a profit.

Indeed, economic theory predicts that the result of forcing a monopsonistic employer to pay higher wages will be to increase employment, as long as wages are still no higher than they would have been in competitive conditions. This is because the higher wages will attract additional workers to accept jobs, allowing the firm to expand the numbers it employs without raising its average labour costs further.

3. In practice, interactions between wage rates, productivity and labour costs may strongly influence the long-term impact of setting wage floors. The simple model assumes that the marginal product of labour is fixed for a given quantity of labour (an additional worker is of a set value to the firm), and that higher wage rates will feed directly into higher labour costs. Neither of these things is necessarily true. An employer obliged to pay a higher wage may look for new ways of making workers more productive, for example by introducing new working practices or increasing training. Long-term labour costs may also be influenced indirectly by wage rates, for example if better paid workers leave their jobs less often and thus reduce the costs of recruitment and induction training. In industries with high turnover, this can have an important effect on costs.

4. Other responses by employers to increased labour costs resulting from a wage floor may be more varied and complex than adjusting employment levels to compensate for the higher 
wage. These may include passing on the additional cost in higher prices (which is more feasible if all one's competitors also face the higher cost of a compulsory minimum wage, making them unable to maintain the original price) and reducing working hours but not the number of jobs. As discussed later, while the latter response is similar to cutting jobs in terms of reducing labour supply, it may be seen as less socially counterproductive than increasing wages for some workers only to make others unemployed. If the same low-paid workers have to put in fewer hours for a similar total pay packet, this could be seen as socially beneficial, although in such a case the question arises of whether that total truly produces a 'living wage', if overall remuneration has not increased.

5. There are strong possibilities of substitution of one kind of labour for another as a result of a minimum wage being imposed, so that overall employment might not change. This may, for example, take the form of more skilled jobs being created to replace unskilled ones, as firms redirect investment into jobs that can support the higher wage. It can also potentially cause substitution by age if, as in some cases, there are different minimum wage rates for different age-groups. However, a nineteenth century objection to minimum wages, which held that there is only a given pot of money available to pay all workers' wages ('wage fund theory') has been discredited. It is now recognised that the amount of wealth that can be allocated to pay is variable, even in the short term, influenced by labour supply and demand.

6. Over the economy as a whole, increased consumption by workers who have had a pay increase can stimulate demand, and therefore improve the quantity of goods that firms can sell at a given price, allowing them to expand production. People on low incomes tend to spend rather than save a high proportion of their income, so this feedback of higher pay into increased economic activity is stronger in low-paying labour markets. The effect, however, is not easy to demonstrate, because the separate effect of a minimum wage is hard to distinguish from other influences on aggregate demand. It might be seen as one factor that helps explain why the overall measurable effect on employment is not as predicted in the model, but it would generally be hard to show that this factor fully cancels out negative effects on labour demand.

It is important to interpret such factors as showing that relationships between wages and employment levels can in practice be more complex than simple economic laws suggest, but not to pretend that these laws are irrelevant. Evidence presented below suggests that the predicted relationship is at best weak in practice, and that in many cases there is no discernible effect of wage floors on employment levels. However, this may be because such floors have been cautiously applied, to a degree or in circumstances unlikely to cause large worker layoffs. The laws of supply and demand remain pertinent, in warning that at some level of enforced higher wages, employers will have no choice but to hire fewer people, or at the very least to reduce opportunities for people with lower skills or less experience. Those pursuing a living wage for all employees cannot completely ignore such a risk.

\section{Wage floors and the labour market: the evidence}

A large number of studies have sought in recent decades to measure the effects of minimum wages on labour markets and firms' behaviour. Initially, the emphasis of most economic research on this 
subject was designed to measure the strength of the effects predicted by the theoretical model, and in particular how serious was the predicted reduction in employment. From the 1990s, however, the studies started to be increasingly empirical rather than theoretical. That is to say, they no longer started from the assumption that the theory was correct, and where evidence did not match its predictions, sought to build alternative models of how the labour market actually works in practice. While this has not resulted in any single clear-cut understanding of how labour markets function, it has had two important consequences. The first is to make it clear, based on a mountain of evidence, that minimum wages do not systematically reduce employment levels. The second is to show, in selective ways, some different effects that they have, such as on prices, wage structures and staff turnover rates. (See Card and Krueger: ix-xxii for a concise summary of this history.)

There is no clear-cut evidence overall that minimum wages reduce the number of jobs, and any observed effects tend to be small

Research can, broadly, seek to identify the effect of minimum wage laws on employment levels in three ways (Dolado et al, 1996: 330-332).

One is to consider 'before and after' effects of a minimum wage law or change in rate. Interpreting this evidence can be difficult because other conditions affecting employment may vary over time, and some of these changes may affect the relationship between wages and employment. For example, a period of strong economic growth may encourage governments to raise minimum wages, but then it becomes difficult to compare the new employment rate to what it would have been in these improved economic conditions had the minimum wage not been raised.

The second is to look at the structure of wages at any one time, in a country with a minimum wage, and to draw conclusions about the extent to which this statutory minimum skews the wage distribution. This however requires adopting a model that makes assumptions, which are difficult to verify, about what would be the structure of wages without an enforced minimum.

A third approach is to look at 'natural experiments', in which there exist at one time two parallel situations that are similar in every respect except the level of the minimum wage. This potentially avoids the weaknesses of the other two approaches of not being able to control adequately for factors other than wage rates that could influence employment levels. Much attention has been given to such natural experiments in the form of neighbouring jurisdictions in the United States where minimum wage rates differ but other conditions are largely similar.

Research in the 1970s and 1980s on impacts of minimum wages in the United States and Europe tended to take the first two approaches, with inconclusive results. In European countries such as France and the Netherlands, the fact that minimum wages were higher as a percentage of earnings than in the United States was seen as helping to explain higher youth unemployment in Europe in those decades, which persists today. However, the minimum wage effect was not clearly demonstrated. It was hard to distinguish this effect from that of other forms of employment protection which could have influenced the hiring of young workers. Moreover, the European countries, unlike the United States, applied lower minimum wages for younger workers, reducing the potential for damage to youth employment (Dolado et al, 1996). 
Research within the United States published in this period appeared initially to show that, as the minimum wage rate fluctuated relative to general wages, teenage employment was higher in periods when the minimum wage was lower - by about a tenth to a third the proportion of the wages difference (see box 3.1). However, the experience of the 1980 s seemed to contradict this finding. The federal minimum wage was frozen from 1981 to 1990 and therefore fell by over a quarter in real terms due to inflation (see Chapter 1, figure 1.1). This appeared to have no stimulating effect on youth employment, as would have been predicted.

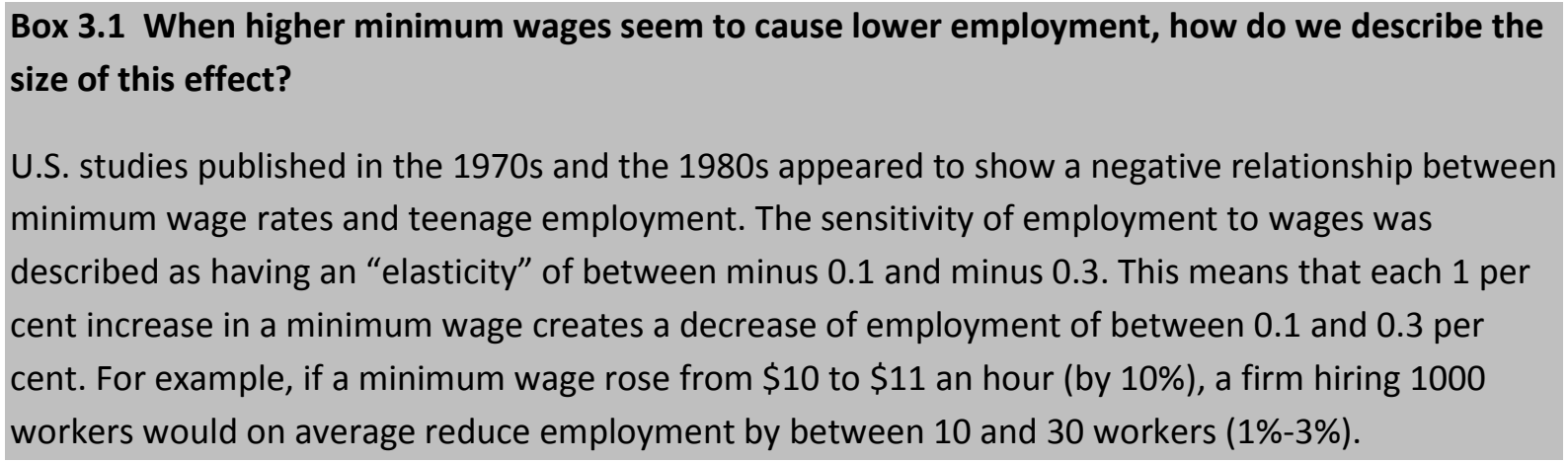

Ironically, the same decline in the value of the US federal minimum that seemed to contradict the theory that lower pay should increase employment also helped create better conditions for testing this theory. By the early 1990s, a number of states were trying to compensate for lower federal rates by setting their own minimum wages. This created the "natural laboratories" of businesses in neighbouring states having to pay different wage rates under economic conditions that in other respects were very similar. The most famous, landmark study looked at wages and employment in parts of New Jersey, which had increased its minimum wage, compared to neighbouring parts of Pennsylvania (an adjacent state), which had not (see box 3.2). The results seemed to show that there was no discernible effect on employment (Card and Krueger, 2016). This was followed by many similar studies of neighbouring counties in different states, reaching a similar conclusion. The most extensive research of natural experiments moved from a case study approach to a generalised comparison, by comparing every pair of adjacent counties over a state border with available data (316 pairs), over a lengthy period, 1990 to 2006. This study (Dube et al, 2010) again found no adverse employment effects.

Such results do not mean that the debate about job losses has been resolved. Some economists, such as David Neumark, have argued that the evidence is far from conclusive, since some studies do show negative effects (Neumark and Wascher, 2008). Many reviews of the evidence, however, have made the point that once you take account of differences in the reliability of results, the evidence shows no systematic effect on jobs. (Schmitt, 2013 reaches this conclusion in a review of "metastudies" which themselves each round up the evidence.) One aspect of this is the potential for results to be affected by background factors that have not been fully corrected for. An example is that some studies have found that regions with low minimum wages have tended to see high employment growth, without taking account of other characteristics of these regions. In particular, the American South has seen relatively strong economic growth, and is also generally conservative politically, electing state governments that are less inclined to raise minimum wages than elsewhere. 
This does not however mean that the lower wages explain the growth, to which many factors have contributed (Dube et al, 2010).

\section{Box 3.2 What happened when fast-food workers got a pay rise in New Jersey, but not round the corner in Pennsylvania?}

In 1992 , New Jersey increased the minimum wage to $\$ 5.05$, while the rate in neighbouring Pennsylvania remained at the federal level of $\$ 4.25$ per hour. This provided a basis for research that is much closer to a clinical experiment than is normally possible in the real world. Using the terminology of experiments based on medical or other interventions, the areas where the wage was changed can be referred to as the treatment group, while those keeping the original wage are considered as a control group, in evaluating the impact of increasing wages.

The easiest way to test this was in a large and relatively standardised part of the US labour market: workers in fast food restaurants. Economists David Card and Alan Krueger surveyed 410 fast food restaurants in the neighbouring states, focusing on the impact on employment rates (Card and Krueger, 1994). Their much quoted study found that far from costing jobs, a higher minimum wage actually had a positive effect on employment in the fast food industry. New Jersey outlets that did not have to raise pay because they were already paying above the new minimum wage had the same employment growth as outlets in Pennsylvania, while those that had to increase their wages increased their employment rates.

The authors suggest various possible explanations for this result that went against received economic theory. The fact that fast food restaurants exert considerable power in the labour market suggests that low minimum wages allow them to employ people at less than what they are worth, andenforced higher wages are not only affordable but draw more people into the job market, allowing the industry to expand. In addition, the higher minimum seems to have fed through into price increases. However, it could not have done so very directly, since price rises were similar where wages had been lower, and therefore were more affected by the increased minimum, as in restaurants where they had started off higher. Yet prices rises affect different products within each restaurant differently: French fries seemed to fall in price and meals to increase, perhaps indicating some marketing strategy of attracting customers in, but still recovering the higher wage costs.

The reality is that economists can offer all sorts of hypotheses about how firms behave, but not confident explanations. This is because company behaviour is so often too complex, taking many factors into account, to be readily explainable through a simple economic model with a limited number of variables. As is so often the case: economists theorise; stuff happens. This stuff, which is external to the economic models, is referred to by economists as "noise", and often drowns out the effects they seek to identify.

It is nevertheless important that the central finding that higher wages did not cost jobs has been confirmed by many other studies throughout the United States. Yet this conclusion has not gone unchallenged. Neumark and Wascher $(1995,2000)$ concluded that in fact the higher minimum wage was associated with a 5 per cent fall in employment in the fast food industry in New Jersey, but the authors of the original study, Card and Krueger $(1998,2000)$, carried out a further study confirming their findings, and pointing to flaws in Neumark and Wascher's work. As so often with competing academic teams, technical disputes about research design can be very hard to resolve. In this case they revolve around the ways in which pay is measured, with Neumark and Wascher saying they had a more reliable series of payroll data over time, while Card and Krueger claimed that this was flawed because Neumark and Wascher's findings could be explained purely by how results were affected by different intervals in reporting pay. 
What happened next?

Research challenging the "minimum wages cost jobs" narrative has had an important effect overall on recent calls for higher minimum wages in the United States, but has not always noticeably affected policies in the states being studied.

Pennsylvania continued to stick to the federal minimum wage rate until 2016, when an increase of nearly $\$ 3$ an hour was approved for state workers and state contractors in the janitorial, landscaping, delivery and food preparation services.

New Jersey continued to maintain hourly rates somewhat above the federal minimum between 1992 and 1997, then from 2006-09 and since 2010, but in intervening periods stuck to the federal rate. Interestingly, a new "natural laboratory" in the region is emerging - but a reverse of the original situation where the higher-wage scenario was tested in New Jersey. In 2016, New York passed legislation to increase the minimum wage towards $\$ 15$ an hour, while New Jersey's governor Chris Christie vetoed a bill to do so, sticking with the much lower $\$ 8.38$ an hour, rising only with the consumer prices index. These two neighbouring states are set to have wages much further apart than New Jersey and Pennsylvania 25 years ago. This could create dream jobs for labour market researchers, if not for New Jersey burger-flippers.

A further important aspect of the US evidence is that impacts, where identified, tend to be small. Figure 3.2 shows the size of effect of various studies. Three particular results stand out. First, for most studies there is only a minorl effect. Second, where the effect is somewhat larger, it is as likely to be positive as negative (a higher minimum wage associated with more rather than fewer jobs). And third (not shown directly on the graph), there is a bias for more reliable or precise studies to give smaller estimates. The overall median elasticity is -0.05 , but the "precision-weighted" median (giving more weight to more reliable results) is just -0.03 . This is only a tenth to a third of the effects estimated in the 1970s and 1980s mentioned earlier in this chapter. That is to say, an increase in a minimum wage from $\$ 10$ to $\$ 11$ (by $10 \%$ ) is associated with a fall in employment in a 1000 -worker firm of just 3 employees ( 0.3 per cent). Given the degree of variability of study results and hence imprecision in estimating the exact level of the relationship, this overall result can be considered negligible.

TEXT:

Figure 3.2: Sensitivity of employment and hours to changes in minimum wage: results of 439 US estimates

Explanation: this chart summarises the results of over 400 calculations within 23 different studies showing the "elasticity" of employment in response to wage changes in different ranges. For example, the greatest number of studies (shown by the highest bar) put the figure at between zero and minus 0.1 - i.e. a 1 per cent increase in pay will reduce employment by up to one out of every thousand workers. Positive results show that higher minimum wages are associated with more rather than fewer jobs. 


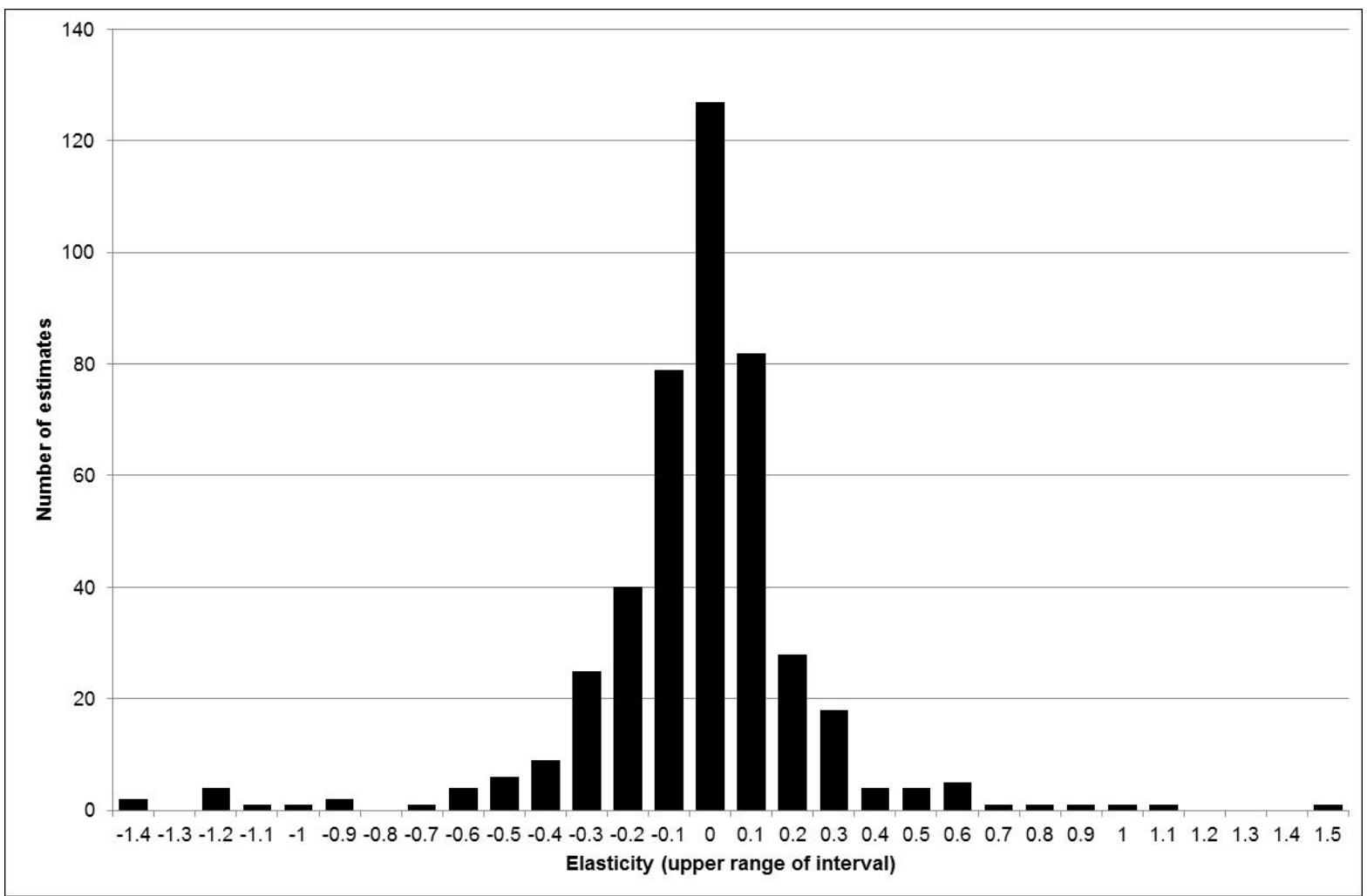

Source: Belman and Wolfson, 2014. Data kindly supplied by authors. 
Outside the United States, the most extensive and systematic research on the impact of a minimum wage has been carried out in the United Kingdom. The Low Pay Commission, which sets minimum wage rates, has a brief to warn against any evidence of wages harming job prospects, and commissions research to evaluate this. Unlike in the United States, the UK does not offer "natural experiments" comparing neighbouring areas at a point in time, since the minimum wage is national. Rather, the research has closely scrutinised differences between employees and sectors affected and unaffected by minimum wage increases. As summarised by a thorough review of such evidence by Metcalf (2008), here too it was found that there has been little or no impact on employment. The context of the UK research is significant. It is part of a process whereby a cautious policy of raising the minimum wage only to the extent that it does not harm jobs is supported by a system for giving a warning signal if such harm is detected. So far this warning has not been triggered. On the one hand, this creates confidence that the minimum wage is beneficial. Were it to be raised to a rate that reduced employment, this could damage the reputation of the minimum wage, even if the harm were relatively minor and if suitable adjustments were then made. On the other hand, by never testing it to that level, it is uncertain whether the process has been overcautious.

This dynamic may now change. In announcing a large, politically-determined increase in the minimum wage for over-25s between 2016 and 2020, and asking the Low Pay Commission to advise on progress towards this level but not on the level itself, the UK government has dropped its former caution. This will be testing the sensitivity of employment to a minimum set at levels not previously tried. The government has predicted a near-negligible effect on jobs - a 38 per cent increase over five years causing a reduction of only 60,000 , or about 0.2 per cent of the total number of jobs. However, this is based on a theoretical model of labour demand which cannot be checked directly against reality, since the conditions that it measures have not previously existed. As described in Chapter 2, a number of US cities and states are also breaking new ground in terms of the rate at which the minimum wage is being lifted, by phasing in a rate of $\$ 15$ an hour, over twice the present (2016) federal minimum. All of these cases have been inspired by living wage campaigns, and thus given comparatively greater weight to moral than to economic arguments. The research showing that fears of economic harm have so far not been realised clearly encourages lawmakers to be bolder in pursuing wages considered to be adequate in covering living costs. Whether this boldness is merited will be tested by future research on economic impacts.

The possibility of substitution of jobs, especially across age groups, must be taken seriously

It is important to distinguish between the effect of minimum wages on overall employment rates and the employment chances of individual groups. In particular, if groups with low wages also have low productivity, efforts to help them by setting a minimum wage will be counterproductive if the result is that firms hire a different set of workers better equipped to produce more. If firms seek to raise production by employing workers with higher skill levels, substitution of less-skilled with better-skilled workers is one possibility, although another, more benign outcome is for employers to train existing workers to become more productive. On the other hand, insofar as productivity is linked to age and experience rather than skills that can be readily acquired through training, displacement of younger, less experienced workers may be the only option.

Many of the studies already referred to focus on employment outcomes for younger workers, since they tend to be the worst paid and the earliest affected by a statutory minimum - especially in the United States where minimum wages do not tend to discriminate by age. The relatively low level of 
US minimum wages, even in relation to teenagers' productivity, helps explain why their employment rates have not been clearly affected. Previous studies showing some effect on teenage employment in the 1970s (when the US minimum was considerably higher) did not identify any compensating effect on adult employment. But in Europe, where adult minimum wages tend to be much higher relative to average pay, the placing of age boundaries and how much below the adult rate the youth rate is set can be key issues (see box 3.3).

\begin{abstract}
Box 3.3 Do young Europeans get priced out of work?
In comparison to the UK and the United States, many continental European countries are often characterised as having relatively "inflexible" labour markets, in which rules about hiring people, payroll taxes and relatively high minimum wages deter employment. This is particularly relevant for young workers whose lack of experience makes them comparatively less productive, and could help explain high rates of youth unemployment seen in some European countries, which in some cases rose above 50 per cent in the wake of the financial crash.
\end{abstract}

An underlying difficulty in identifying the role of minimum wages in contributing to this phenomenon is that their influence is hard to distinguish from other, highly distinctive features of employment conditions in each country. Many European countries have complex employment regulation, and apply it in different ways to different groups of workers. Even when considering the price of hiring people, minimum wages need to be looked at in combination with "social charges": the payroll taxes imposed on firms to help fund social security and other programmes, which can make the total cost of hiring someone considerably greater than their pay. One study found for example that while the United Kingdom and Spain set minimum wages at an identical percentage of average wages, employers had to pay an additional $31 \%$ in payroll taxes or social insurance contributions in Spain but only 7\% in the UK for a full-time minimum wage worker (in 2005: see Immervoll, 2007).

One thing that is clear is that there is huge variation in different European countries. Figure 3.3 compares their minimum wage and youth unemployment rates. It shows that German-speaking and Nordic countries, which have not used general minimum wages but rather tailored wage regulations to different industries and occupations, have succeeded in keeping youth unemployment extremely low. Germany is often compared to France (for example by Cahuc et al, 2013) in these terms, with the suggestion that France's high minimum wage rates explain why its youth unemployment is so much higher than Germany's. However, the graph shows that Italy has no minimum wage but higher youth unemployment than France, while countries like Greece and Spain have much higher youth unemployment than others such as the United Kingdom and Luxembourg, despite minimum wages being at similar levels (relative to median wages in each country). This does not mean the level of the minimum is irrelevant, and in some cases specific design features may contribute to these results. Luxembourg and the UK both have lower minimum wage rates for young people; Spain does not, and Greece only for workers in new jobs (see OECD 2015).

Figure 3.3 Minimum wages and youth unemployment rates in 21 European countries, 2013 


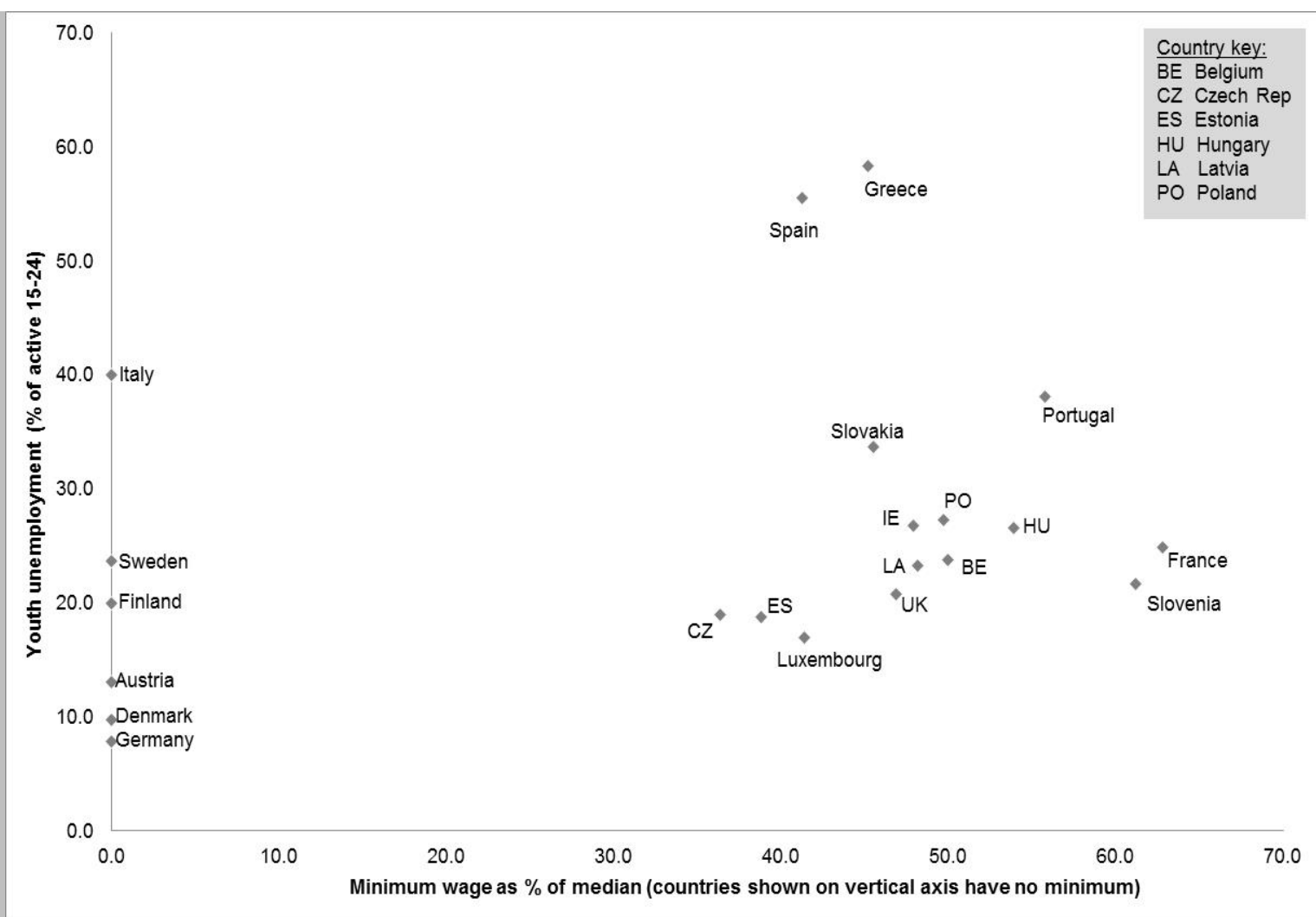

Sources: $O E C D$ and Eurostat data

While comparing the effect of national wage levels in neighbouring European countries does not offer the same "natural experiments" of their effects as in neighbouring US states - because economic and regulatory conditions can be so different across national borders - evidence within European countries over time has demonstrated some tangible effects, particularly for young workers, where there is rapid change.

A clear-cut example is the experience of Portugal after a minimum wage for 18 and 19 years olds, which had been set 25 per cent below the adult rate, was abolished in 1987 . This stark change, effectively raising the minimum for 18-19 year olds by a third, produced a substantial drop in employment for this age group, and a significant although smaller associated increase in the employment of 20-25 year olds. Importantly, there was no effect on the rest of the working age population, since the kinds of jobs affected were not usually done by adults older than 30 . In this case, therefore, both an overall reduction in jobs and a degree of substitution of slightly older workers resulted from the increase (See Pereira, 2003).

In Spain, on the other hand, studies in the 1980s and 1990s suggested that the effects of minimum wage increases were restricted to substitution rather than net job loss: a 10 per cent increase in the minimum wage was found to reduced youth employment between 1.5 and 6 per cent, but without an overall reduction in employment (Perez Dominguez, 1995; Dolado et al, 1996; Gonzalez Güemez, 1997). However, these studies were carried out before the abolition of youth rates in 1998, and before a politically driven increase by a third in the mid-2000s. Some authors suggested this was likely to have had a substantial effect on youth employment (Perez Dominguez and Gonzalez Güemez, 2005), but there is no clear-cut empirical evidence of whether this is the case. In the 2015 and 2016 general elections, trade unions and the left wing party Podemos called for a substantial increase. This may seem ambitious, given that youth unemployment in Spain, despite having been reduced somewhat from its peak, remained above 40 per cent. 
Overall, then, evidence of effects of minimum wages in Europe has been selective and far less empirically grounded than in the United States. The difficulty in collecting definitive evidence in the absence of natural experiments within countries has influenced this, and political pressures for higher wages have appeared to weigh more heavily than any real attention to evidence about their effects. The United Kingdom was the exception to this up to 2015, with a Low Pay Commission policing a cautious approach, but as referred to above, this may now be changing.

An important argument for setting younger adults' wages at a lower rate is that they need a chance to acquire skills, by being paid less a time when they are relatively less productive. If employers are deterred from hiring them on this basis, it is argued, they will lose out by never getting a chance to acquire these skills. The centuries-old practice of apprenticeship involves workers spending a period on very low wages while they are being trained. This practice can also be related to the issue of a living wage: many young adults have lower living costs, for example because they are not yet raising a family. Historically, apprentices often lived with their employers in very simple conditions. Yet both the accuracy and the ethics of this assumption can be criticised. Some people start a family at age 18 , others at 40, so age-based pay rates will not accurately reflect the different costs that people face. And on a point of principle, an attempt to vary pay with living costs is problematic. People working side by side do not get paid different amounts according to the size of their families, so why should they purely on the basis of chronological age? This explains why, for example, the living wage rate accredited by the UK's Living Wage Foundation uses a single calculation for all workers.

Age-discriminating minimum wages may nevertheless be seen to be realistic in terms of preventing jobs from being lost by workers at an age where on average they are relatively unproductive. A projection of what would be the impact on labour demand if all UK employers adopted the voluntary Living Wage in the UK (representing a "worst-case scenario", not a forecast of actual employment effects), without any youth rates, showed an overall reduction of 160,000 jobs but a reduction of 300,000 for unskilled workers aged under 21 (Lawton and Pennycook, 2013). This implied that for workers not in this category, employment demand would rise by 140,000 .

A contrasting strategy was adopted by the UK government when it introduced its "national living wage" in 2016: the compulsory minimum is increasing sharply for over 25s, but not for other age groups. This has introduced a new gap between minimum wages for under-25s and over-25s, which will grow over time. Potentially this could lead to displacement in the opposite direction to the normal transfer from younger to older workers. In industries such as hotels and catering, where employment security is often low, there could be a strong incentive to stop hiring workers once they reach their $25^{\text {th }}$ birthday.

There is thus no perfect solution to the alignment of wage floors with age. With or without differentiation in the rate by age, there will be cases where the pay rates and value of workers at different ages will not be perfectly aligned, causing employers to prefer to hire a worker in one age category over another.

The issue of substitution by skill level can be more complex. One possibility is that the least qualified workers are disadvantaged by pay floors that make employers more selective about whom they recruit, and also that increased labour costs make them less inclined to invest in training. Alternatively, minimum wages could encourage employers to invest in existing workers and give 
better incentives for workers to acquire skills and to put more effort into searching for rewarding work. Evidence on this is inconclusive, suggesting that different employers and employees have adopted different strategies (Schmitt, 2013).The behaviour of both employers and employees depends on the nature of particular jobs. In some cases there will be fairly simple ways of making existing workers more productive by giving simple instruction in some new techniques. If in contrast an employer seeks better educated workers to do better paying jobs in new ways, less educated individuals may find it harder to gain employment.

\section{Any reductions in employment may affect hours as well as jobs}

The potentially harmful impact of minimum wages is sometimes expressed as "Minimum wages could cost jobs". However, it is possible that reduced demand for labour results not in a reduction in the number of jobs but rather in the number of working hours of existing employees. This is a crucial distinction when considering the desirability of minimum wages from the perspective of low paid employees. A reduction in hours but not in jobs can potentially avoid creating losers, if the size of the wage increase is proportionately higher than the reduction in hours (see box 3.4).

\section{Box 3.4 - Why better pay but lower employment may avoid creating losers}

Arguments about wage floors tend to assume that they are counterproductive if they reduce employment. But should the combination of higher pay and less work always be seen as harmful? One issue, raised earlier in this chapter, is the strength of this effect: if many people are better paid, a very small reduction in employment may be seen as a price worth paying. A further point to consider is whether it needs to harm anyone, if the cut in employment is shared around.

If Jim gets a pay increase but as a result Jane has no job, there is a winner and a loser. If Jim and Jane both get pay increases but their working hours reduce, both will be winners, as long as total pay rises. This will be the case as long as the percentage increase in pay exceeds the percentage reduction in hours. In economic terms, this is expressed as elasticity of demand for labour being between zero and minus one. Note that where elasticities have been estimated (see above), they have been only a fraction of this amount - that is, the amount of work falls proportionately much less than hourly pay increases. Note also that the benefit to workers in this case is not just that total pay increases to make them financially better off, but also that they have more leisure time - an important consideration for people who may have had to work long hours to make ends meet, or who are juggling working and caring responsibilities.

Evidence on the association between wage floors and working hours in the United States has been weak and inconclusive. In the United Kingdom, there is evidence that the introduction of a National Minimum Wage in 1999 caused about one in ten workers whose pay it affected to reduce their hours, (Stewart and Swaffield, 2002) and that the average reduction for all workers whose pay was affected (including those with no change in hours) was between one and two hours a week(Stewart and Swaffield, 2004)..

\section{Higher wage costs may be offset by lower staff turnover}

Higher wages may be expected to increase the cost of labour for employers, but this effect may be modified by changes in the cost of employing people other than pay costs. In low-paying sectors, which tend to be typified by high staff turnover, the cost of hiring people may be substantial. This 
can be felt in a number of ways, including the costs of advertising a job, the greater cost of running the human resources department, the impact on business of having an empty post for a time and the lower output of a new worker while they are being inducted or trained. Reducing turnover rates can thus produce substantial gains. When workers feel that they are adequately paid, they are less likely to seek work elsewhere, and this may also be influenced by a sense that they are being more valued, especially where voluntary "living wage employers" proclaim this status as a sign of caring about their workers.

The same United States studies that have found limited employment differences in restaurants in neighbouring counties with different minimum wages have also found that turnover rates fall substantially following a minimum wage increase (Dube et al, 2010). They have found similar results in publicly contracted services where living wage ordinances have been imposed. Evidence in the United Kingdom also highlights staff turnover as the single most important change associated with introducing a voluntary living wage, with absenteeism also falling. One study for example (Wills and Linneker, 2012) found that in a sample of London employers taking up the Living Wage, turnover had reduced by an average of 25 per cent, although in light of small sample sizes these results must be taken as indicative. Another UK study, examining data on pay rates and job changes, found that when the national minimum wage increases, those who benefit the most have a relatively high chance of remaining in their job compared to those with a smaller or no benefit (Dickson and Papps, 2016).

\section{Higher wage costs are sometimes passed on to consumers through price}

One way for a firm to pay people more is to increase its prices. In a completely free market, this may not be an option, because the firm will be undercut by a competitor paying lower wages and charging lower prices. However where all employers in a country or state must pay a minimum wage, this undercutting is no longer possible, at least from employers covered by the same rules. If competition goes beyond these boundaries, for example in goods traded internationally, there is still a problem. However, most low paid jobs are in "non-exportable" jobs in service industries. If a fast food restaurant raises its prices because wages must be higher in the local area, another worker living hundreds of miles away cannot produce the same service more cheaply from a distance.

In both the United Kingdom and the United States, there is evidence that part of the cost of raising minimum wages has been passed on to consumers. The most extensive study of this subject in the UK (Wadsworth, 2007) suggests that after the introduction of the National Minimum Wage, prices rose by 0.8 per cent a year faster than average in affected industries. This evidence also rejects a theory that such an effect neutralises the benefit of better pay, because low-paid workers tend to consume services (such as pub drinks and takeaway food) produced by other low-paid workers. This is true for some low-paid industries, but for others, such as dry cleaning and hairdressing, the reverse is true, so higher prices have fairly even effects across the population. In the United States, a review of the evidence also showed a distinct but small price effect, suggesting that increasing a minimum wage by $10 \%$ raises general prices by about $0.4 \%$ (Lemos, 2008).

The effects may depend on the state of the economy

One difficulty with considering overall effects of evidence on wage floors is that they have been carried out in different places and at different times, when conditions may affect the outcome in 
different ways. This is especially important because economists so often draw on the past to try to forecast the future. At any one time, the economy is operating in a unique context which has never been experienced before, requiring caution in making such projections.

It is perhaps not coincidental that some of the most significant increases in minimum wages have come in good economic times. Reflecting on substantial increases in minimum wages implemented in the 1990s, the chair of President Bill Clinton's Council of Economic Advisors, Laura d'Andrea Tyson (2013) has commented: "a higher minimum wage did not impede robust employment growth; it did contribute to healthy income gains for low-wage workers"

In contrast, some studies have reported higher risks to jobs of raising the minimum wage during a recession. It is important to note that such studies do not show a general effect on jobs, even when the economy is weak, but rather that there may be effects in areas where job prospects are already relatively low. For example one study (Addison et al, 2013) found that in the United States from 2007 to 2009, employment effects were seen only in states where unemployment was high. Another study (Gorry 2013) comparing the US and France suggested that in the latter, the impact of the minimum wage on jobs in recession had a greater employment effect because of a higher unemployment baseline. Such evidence does therefore show that any increase in a wage floor during a recession will cost jobs, but that its impact must be looked at carefully in combination with other conditions, particularly to avoid further harm to groups who already have a weak position in the labour market.

\section{Publicly contracted labour markets may operate differently}

A private employer raising the wages of low-paid workers faces a range of choices, including producing less, raising prices and changing the nature of their product. For public employers and firms supplying services to the public sector, the options may be different. For a public body directly employing labour, 'raising the price' may not be an option where tax revenues are fixed. There may also be a legal obligation to supply a certain amount of a service to the public, although the quality of this service may be hard to enforce. On the other hand, some effects of better pay noted above can apply across sectors, including the benefits of lower staff turnover and the incentive to take measures to increase staff productivity.

For private contractors, being required to pay a 'living wage' may encourage more competitive bidding for contracts, as well as pruning profit margins. On the other hand, contractors may also pass on higher costs to public clients. Just as private companies being forced to pay a higher minimum wage can raise prices without fear of lower-paying competitors undercutting them, so bidders for public contracts may increase their fees on this basis. Indeed, research in this area suggests that many bidders welcome the "level playing field", and the chance to bid on the basis of a high quality service rather than low price based on low pay (Brenner, 2004). Overall, this research shows that there have at most been very modest increases in city contracting costs in the United States.

In the United Kingdom, on the other hand, the projected 38\% increase in minimum wages for over25s between 2015 and 2020 (see Chapter 2) is likely to bring a very specific problem to one area of public contracting: social care. This sector has a high proportion of low paid workers, relatively few aged under 25 and limited opportunities for improving productivity, at least in the short term. 
Previous evidence (Machin, Manning and Rahman, 2003) showed that when the UK first introduced a minimum wage in 1999, this caused many of its workers to get substantial pay rises, and that employment appeared to fall, although by reltively little considering the magnitude of pay increases. After the introduction of the "national living wage" brought another steep pay hike for many care workers in 2016, there was an increased "bunching" of their pay rates, as there had been in 1999, bringing the proportion of care workers on the statutory minimum up to one in three.The higher this proportion, the bigger the impact of further increases on the overall pay bill. There had not by 2016 been any further noticeable effect on employment levels. However, with public budgets tight and the compulsory wage still set to increase steeply, existing service levels and employment rates in the sector will become increasingly difficult to sustain.

\section{Workers earning above a wage floor could be affected in various ways}

The most obvious direct effect of a minimum or living wage is to dictate the pay rate of anyone who might otherwise have earned below the level set. Raising a minimum wage to $\$ 10$ an hour means people previously paid $\$ 9$ will earn $\$ 10$. But what about people previously paid $\$ 11$ an hour? Three outcomes are possible. Either their pay could remain at $\$ 11$, causing a "flattening" of pay structures. If $\$ 9$ an hour workers had been supervised by people on $\$ 11$, the difference between their wages will halve, from $\$ 2$ to $\$ 1$. This may reduce incentives to seek promotion and make people taking on more responsibilities think that they are being poorly rewarded for doing so. To avoid this, employers may alternatively seek to preserve a differential of $\$ 2$, raising supervisors' pay to $\$ 12$, or by a smaller amount in order to reduce the effect on differentials. The opposite effect would be to cut back on better-paid workers' wages, in order to help cover the cost of the minimum wage increase. While they are unlikely to reduce supervisors' pay directly (for example to \$10.50), they may avoid increasing it over time as they might otherwise have done, causing further convergence of pay at different grades as the minimum wage rises to cover inflation. Which of these strategies is adopted has significant effect for opportunities for lower-paid workers and their ability to progress to better living standards.

A survey of employers' intentions after the announcement of the UK's "National Living Wage" in 2015 suggests that in practice higher wage floors will have varied effects on wages above the floor, rather than pushing them in any single direction (CIPD, 2016). Faced with an immediate prospect of an increased minimum wage for over-25s by more than $10 \%$ in the first year and further increases in the pipeline, only $9 \%$ of employers envisaged reducing the rate of pay growth for the rest of the workforce. Greater proportions thought they would help cover the extra cost of the higher minimum in other ways such as raising efficiency or productivity (30\%), taking lower profits or absorbing the costs $(22 \%)$ or raising prices $(15 \%)$. On the other hand, somewhat more employers $(26 \%)$ thought that they would reduce differentials between workers affected by the National Living Wage and their supervisors or managers than employers who thought that they would preserve such differentials (20\%). (Half of those surveyed had not yet decided what to do.)

If the long-term effect of higher wage floors is to cause a flatter wage structure among lower-paid jobs, this could be looked at in one of two ways. On the one hand, it could be seen as exacerbating a trend known as the "hollowing out" of the labour market, whereby there are more well-paid and poorly-paid but fewer medium-paid jobs than in the past. Some highly-educated workers are well paid for their sought-after skills in the "knowledge economy"; others without these skills provide 
low-value routine services (such as shelf-stacking) at low pay. Higher pay floors could undermine jobs in the middle, such as supervisory jobs, by causing employers to focus on pay for the least skilled. On the other hand, in order to make it viable to hire such workers at the higher rate, there will be pressure to increase their skills and productivity. Thus, while such a policy will not restore the jobs in the middle, it could help transform the jobs at the bottom, narrowing the gap that has opened up between well-paid and poorly-paid employment.

\section{Commentary}

Few aspects of economic theory have had as great an influence as the idea that an attempt to set wages at a fixed minimum will be counterproductive because those able to command the lowest wages in the market will then become unemployed. Yet decades of research have failed to confirm this theory in practice. Some economists stick to the theory, pointing to certain cases where it appears to have been accurate, and warning of the risks of ignoring it. Others argue that the theory needs to be adapted to the way in which labour markets actually work.

Some have tried to build alternative models from the "neoclassical" relationship shown in the graphs at the start of this chapter. For example, they suggest that, while labour markets are not as monoposonistic (dominated by a single local employer) as they may have been when one company could dominate employment in a town, there are still "frictions" that prevent them from operating completely freely. By this they mean that while workers are not obliged to stay with one employer, changing jobs has enough difficulties to allow firms to set wages lower than they would if workers were perfectly mobile. However, any effort to model the effects of such markets cannot represent a universal reality as in the simple model, since conditions vary greatly from case to case.

Rather than a single set of rules about the effect of wage floors on labour markets, then, the evidence points to a series of ways in which employers and workers may respond. These include reducing working hours, making labour more productive (either with the same set of workers or through different hiring practices) and raising prices. Other knock-on effects may be to diminish profits or reduce staff turnover.

Some of these impacts may be wholly benign. If wages can be increased without raising labour costs because staff become more loyal and recruitment costs decrease, everybody wins. If paying a decent wage encourages employers to find ways of using labour more effectively, additional costs will be offset. Often, though, the effects involve winners and losers. While workers will be net winners if they end up working fewer hours for more total pay, this is likely to reduce profits, and thus represents some loss in revenue to shareholders or company owners. If minimum wages drive up prices, the workers in the industries affected gain at the expense of its consumers. In both of these cases, this may be seen as justified - because low-paid workers are seen as being exploited to allow holders of capital to make unusual profits through market power, and by providing services to consumers at unjustifiably low prices.

Thus, paying workers enough to live on comes back to a moral choice with consequences for the distribution of economic well-being. But can pay floors truly be effective in ensuring that workers and their families have enough - as suggested by the paradigm of a 'living wage'? This depends on the interaction between a worker's wage and the overall income of their household, which is 
affected by many other factors as well as wage rates. Chapter Four therefore puts the living wage debate in the wider context of approaches to tackling low income. 